2020, Volume 10, International Conference Globalization, Innovation and Development. Trends and Prospects (G.I.D.T.P.), pages: 308-316 | https://doi.org/10.18662/lumproc/gidtp2018/34

\section{Social Responsibility versus Managerial Performance as a Psychological Strategy in Human Resource Management}

\author{
Laurentiu BARANGA ${ }^{1}$, \\ Simona-Maria BARANGA ${ }^{2}$, \\ Rareş Vladimir NIT, $U^{3}$
}

${ }^{1}$ Professor PhD. "Valahia" University of Târgovişte, Romania, barangalaurentiu@yahoo.com

2 Professor PhD. C.N.I. „Matei Basarab", Rm. Vâlcea, Romania, simonamaria.maracine@yahoo.com

${ }^{3} \mathrm{PhD}$ student, U.S.A.M.V. Bucureşti, România, nitu.rares.vladimir@gmail.com

\begin{abstract}
Staff recruitment, benefits systems, professional training programs, internal communication, health, employee safety, their involvement in community life and their attitude to the environment, stress management, change management - all get a new dimension if they are addressed from a double perspective of organizations that are aware of the social impact. Over time, the concerns of psychologists and managers about explaining human behavior have given rise to a number of motivational theories. This paper presents 3 motivational theories which are considered more important, namely:

- the theory of content - emphasizes the specific factors that motivate employees as individuals. These individuals can originate in themselves, referring to certain necessities and aspirations; or they belong to the micro-context in which they operate, that is, the position they occupy;

- the motivation process theory focuses on the dynamics of motivation, starting with the initial energizing of behaviors, continuing with the selection of alternatives and reaching the current effort. The process theory emphasizes psychological processes or forces that have an effect on motivation as well as on primary needs;

- the instrumental theory asserts that rewards or punishments serve as means to cause people to behave or act in different ways.
\end{abstract}

Keywords: responsibility; performance; motivation; psychology; recruitment.

How to cite: Baranga, L., Baranga, S.-M., \& Nițu, R.V. (2020). Social Responsibility versus Managerial Performance as a Psychological Strategy in Human Resource Management. In I. Panagoreț \& G. Gorghiu (vol. ed.), Lumen Proceedings: Vol. 10. International Conference Globalization, Innovation and

Development. Trends and Prospects (G.I.D.T.P.) (pp. 308-316). Iasi, Romania: LUMEN Publishing House.

https://doi.org/10.18662/lumproc/gidtp2018/34 


\section{The relationship between motivation and performance}

The basic conditions for professional satisfaction can include greater comparative pay, a fair pay system, real opportunities for promotion, participatory management and attention to the needs, desires and feelings of the people, a reasonable degree of social interaction in the work environment, interesting and varied tasks, and a high degree of autonomy: controlling the pacea of work and working methods. The degree of satisfaction achieved by individuals depends to a large extent on their own needs and expectations, but also on the working environment.

However, no obvious connection has been established between satisfaction and performance. A satisfied worker is not necessarily a highly productive professional, and a high-productivity professional is not necessarily a satisfied worker. The assertion that good performance leads to satisfaction, rather than vice versa, has not been proven.

\section{Employee Performance Assessment}

Performance assessment is the activity of comparing and comprising the obtained results, the physical-intellectual, professional and managerial potential with the objectives and requirements of the occupied position [1].

In the eighth decade, a stream of thinking, namely performance management, emerged, according to which performance assessment requires not only the measurement of results but also the analysis of the behavior that led to the achievement of the results.

Performance management leads to the determination of strengths and weaknesses of employees and to the identification of forward-looking performance solutions. It also gives employees the opportunity to discuss their problems and aspirations. In this way, the evolution of performance turns from a stressful process into a permanent and constructive one.

In some authors' opinion, evaluation is considered to be all the processes through which value judgments are made on employees in the enterprise, considered separately as holders of certain positions, in order to reassess the essential elements of how to achieve the objectives and tasks assigned and exercising competencies and responsibilities, rewarding and sanctioning, setting up ways to improve training, and shaping the prospect of promotion [4]. 


\section{Motivation and performance the optimal motivation}

Motivation is not just a theoretical concept, an end in itself, it is and must be a precious "tool" increasingly used by leaders to achieve superior performances, meaning by performance in particular to achieve goals in optimum consumption and (lower) costs and( higher) quality, etc. Only this way explains the increased interest of practitioners towards motivation, a concept that has not until recently been highly theoretical.

The relationship between the intensity of motivation and the level of performance is dependent on the complexity of the activity (task) the individual has to accomplish.

In simple tasks (repetitive, routine, automated, with fewer solutions), as the intensity of motivation increases, performance levels also increase.

In the case of complex tasks (creative, content-rich and solving), increasing the intensity of motivation is associated up to a point with increased performance, after which the latter decreases. This development was demonstrated by Yerkes and Dodson in a research conducted in 1908. On the same occasion, the optimal motivational concept was launched, namely an intensity of motivation to achieve high performances or at least those expected, in particular in two situations, namely:

- when the difficulty of the task is correctly perceived by the individual; In this case, the optimal motivational means the correspondence, even equivalence, between the sizes of the two variables (for example, if the difficulty of the task is high, it means that there is a great need for motivation to accomplish it, if the difficulty is medium, medium intensity motivation is sufficient, etc.);

- when the difficulty of the task is perceived incorrectly by the individual, in this case, the individual will not be able to mobilize the energies and efforts necessary to accomplish the task.

The difficulty of the task can be assessed incorrectly, underestimating it (in this situation the individual is sub-motivated, acting in the conditions of an energy shortage, which will eventually lead to the failure of the task) or overestimating it, which causes the individual to be overmotivated and act under the conditions of an energy surplus that could disrupt, stress, spend energy resources before confronting the task, etc.

Under these circumstances, in order to obtain optimal motivation, a slight imbalance between the intensity of motivation and the difficulty of the task is necessary.

For example, if the difficulty of the task is medium but incorrectly assessed as high, then an average intensity of motivation is sufficient and, therefore, slight submotivation is required. If the difficulty of the task is 
average, but considered - incorrectly - as low, an average intensity of motivation is sufficient and therefore a slight supermotivation is indicated.

Here, the following conclusions can be drawn:

- intrinsic reasons lead to greater and more stable performance over time than extrinsic reasons;

- extrinsic reasons may be negative and positive. The latter are more efficient - both productive and human - than the negative ones. It is preferable that negative extrinsic motives be applied only in exceptional situations and for quantitative performances that require simple activities.

Positive extrinsic reasons have an important role in motivating performant activities.

In order to achieve the optimal motivation one must consider a permanent combination of positive extrinsic motivation and intrinsic motivation to achieve not only the increase in performance but also the development of the human potential of personal life.

\section{Increasing managers' effectiveness in achieving motivation}

The ability to make people work with you and for you, in short, the art of motivating others about common goals is essential to the success of any manager [2]. At the same time, this opportunist by excellence (manager) is almost exclusively concerned with the operational character of motivation. In the activity of modern leaders, the prediction of the behavior of their collaborators is essential, and even if it is extremely difficult to predict the specific behavior of each and every one of them, the specialists must identify not only who is responsible for a particular behavior but also how it can be influenced; in essence, only identifying causes is a sterile action without echo in the management process if they can not act on their basis. Behavioral sciences must therefore provide him, first of all, even if speculation and theoretical analysis are interesting, the answer to the fundamental question: can people be motivated? and implicitly to elucidate the notion of directed behavior. Regardless of the negative connotations that the notion awakens us (until manipulated behavior is not a noticeable distance) we are dealing with a concept much more known and used by everyone.

A brief analysis of life experiences will highlight that usually many of human actions are preceded by anticipation of what interlocutors, voters, collaborators, friends, family, etc. are expecting from us, we behave as we hope we please (or disturb) others. Success is conditioned by either clear information or by foreseeing expectations. 
Therefore, simplistically, through directed behavior we must understand the direction of another person's favorable reaction through behavior in consonance with their desires, their hopes.

Note that, in fac,t the manipulated person is not the collaborator, but the leadership framework that, in order to motivate their employees, must have the behavior as close as possible to their expectations[5]; in fact, this change of meaning is one of the fundamental changes in modern leadership style.

The purpose of this subchapter is to show what managers need to know so as to improve employee performance by directing their behavior, motivating them.

Possible responses were sketched out by looking at the forms of motivation, knowing that each form corresponds to specific types of motivation that cause people to work. The training and, to a possible extent, the most accurate knowledge by managers of these reasons with the help of observation and even diagnosis is an essential condition for the ability of leaders to respond to the challenge.

Identifying real reasons can often be a difficult process, as there is a risk that managers may consider their own motivations when they appreciate their collaborators. In other words, knowing the real motivations of employees does not have to be, above all, an intuitive process without excluding it, but must be based on a whole motivational tool. It is very easy to have misconceptions about what makes people work or not. If the diagnosis is incorrect, then measures to correct existing situations may be totally inappropriate.

The fundamental change brought about by the new approach to human resource management is that the goal is no longer to engage people in the given parameters, but the goal becomes their involvement in the enterprise's business to the fullest extent possible.

We are no longer dealing with individually set performances, but with enterprise-level goals, the individual being drawn to their achievement.

To achieve this goal, a leadership framework has a wide variety of tools such as:

- enhancing the self-confidence of workers in order for them to become motivated to engage in complex activities;

- capitalizing on work by creating opportunities for obtaining satisfaction and avoiding dissatisfaction at work or by building a climate of appreciation of well-done work;

- ensuring constructive competition;

- providing a stimulating pay system;

- delegation, etc 
The success of using these tools depends on the existence of a correlation between the person and the position they occupy. In order to be able to implement, with the chance of success, the motivation methods and techniques, when designing the positions, the motivational implications must also be taken into account in order to obtain the best person-to-position correlation.

By starting with "the right man in the right place", it is much easier to act in accordance with the new optics brought about by the training and motivation of the workers.

Another aspect to be taken into account when it is argued that managers need to know motivation is that one can speak of individual motivation, but also of group motivation. The reason why the group motivation is debated is precisely the fact that the enterprise is a social group and, as any society, it brings about specific needs. Group motivation being a specific problem area, the idea of pproaching it in a marketing manner occurred, thus defending internal marketing as an effective way of practising human resources management [3].

This is the second time we refer to this parallel field, being justified this time, too. What would be the hiring of leaders in internal marketing?

It would involve, first of all, the establishment of the product for sale.

This is, of course, its organization and leadership. The company has: identity and image, leaders and their personalities, plans and projects for development, organization and functioning, development possibilities, working conditions, climate and environment, products and services, etc. By motivating to attract employees to the objectives of the enterprise, it is obvious that the employee's accordance to the requirements of the enterprise becomes a conscious and professional assumption.

Secondly, it is necessary to establish the market for conquest. This consists of the entire staff of the enterprise, with its unique characteristics: personality and culture, experience and knowledge, technical and human skills, responsibilities, belonging and origin etc.

Thirdly, it is the commercial relationship, namely the humanorganization relationship, always pursuing the optimization of the interactions. If "external marketing" pursues economic goals, internal marketing pursues social ends (enhancing human capital).

For a secure diagnosis, the internal marketing approach starts with a process of knowing and understanding of the internal market. We refer in particular to knowing the motivation of this market, namely:

- detecting the expectations and needs of the company's employees; 
- assessing levels of satisfaction or dissatisfaction with business development policy, leadership style, organization and way of operation;

- images produced by enterprises or their services;

- the terms of the employment contract, etc.

Taking into account the aim pursued, namely increasing work performance to achieve business objectives, internal marketing is precisely the set of methods and techniques that, in practice, use logic to allow businesses to increase performance in the interests of both customers and to their own collaborators.

In conclusion, the concern of managers to get the maximum from their employees must take into account both the motivations of each individual and the specific motivations at the level of the group. Only together these two levels of approach allow the knowledge of the real situation and the consequent measures to be taken.

A list of such measures, in fact practical steps that can create and sustain a motivating work environment can be the following:

- setting exciting, yet realistic and achievable goals; the manager must involve employees in determining their own goals; people need to feel they have control (total or at least partially);

- informing employees about the decisions that will influence their work and, in fact, about any important aspect related to the organization;

- increasing individual responsibilities through more delegation; the activity should be distributed so that everyone has the chance to assume more responsibility and gain more experience;

- employees' clear understanding of the fact that achievements and failures depend on the clear definition of the relationship between effort and reward (ensuring that employees have correctly understood this relationship);

- recognizing employees' achievements without banalizing rewards by distributing them too easily.

These measures, in fact, are the basis for good employee management and motivation does not seem to be such a nebula as it sounds to many people.

The rich motivational instrumentation includes many theories of motivation, each of these theories presenting certain models of not only theoretical value but also special practice. 


\section{Staff motivation requirements}

Managing effective motivation involves and also demonstrates the experience and performance of many organizations in the developed countries, their compliance with a set of requirements, namely:

- employing and using within the organization people who appreciate the results it provides. rewards.

- determining the items that people want and offering them as

- ensuring employees at all times with interesting tasks that "defy" theirbpossibilities, self-indulgence, creativity, using methods such as: switching positions, widening the content of functions, enriching positions etc.

- customizing the motivations as a way, size and way of granting according to the characteristics of the employees, up to their personalization.

- providing incentives, especially economic, to gradually save resources and provide motivational and professional prospects for long-term employees, based on reasonable and affordable expectations.

- communicating the employees, very explicitly, the tasks, the level of achievements and the expected performance.

- employing employees on the positions that suit them, so that they like what they do, thus achieving their self-compensation.

- combined use of economic and moral-spiritual rewards.

- informing employees about the rewards and sanctions provided by the actual results.

- providing economic and moral-spiritual rewards at different times, as needed.

- applying economic and moral-spiritual motivations immediately after completing the scheduled work processes.

- minimizing staff sanction.

- provide employees at all times with those rewards that they want and still await.

- motives for employees to be perceived by them as appropriate.

The examination of these requirements results in their comprehensive scope, starting from the selection of staff itself, as well as from the treatment of motivational processes in their dynamics. In other words, it is intended to prevent the phenomenon of moral wear and tear of motivations. It can also be observed that motivation is not addressed in itself, but integrated into managerial processes and relationships, especially those of an organizational nature. 


\section{References}

[1] Căprărescu Gh. „Evaluarea, perfecționarea şi promovarea personalului de conducere, Management”. Bucureşti: Editura Didactică şi Pedagogică, 1992: 251.

[2] Caprarescu G, Stancu DG, Anghel G. Managemenetul resurselor umane, Sinteze, grile, studii de caz. Bucureşti: Editura Universitară; 2009.

[3] Kotler P. Managementul marketingului. București: Editura Teora; 2008.

[4] Nicolescu O, Verboncu I. Management. Bucureşti: Editura Economică; 1997: 459.

[5] Prodan A, Rotaru A. Managementul resurselor umane. Bucureşti: Editura Sedcom Libris; 2006. 